\title{
RADON-222 CONCENTRATION AND ELECTRICAL CONDUCTIVITY IN THE ATMOSPHERE OVER THE INDIAN OCEAN
}

\author{
M. Okino, T. Tanji and S. Mochizuki \\ Department of Engineering, Muroran Institute of Technology \\ 27-1, Mizumotocho, Muroran 050
}

\begin{abstract}
Observations of radon decay products and atmospheric electrical conductivity in the atmosphere on the sea surface were made by ship mainly over the Indian Ocean from July to September, 1993.

Even at mid ocean and also at the Philippine sea, the radon concentration and the electrical conductivity were found to vary with considerable fluctuations. Radon concentration levels were ranged from $6.6 \times 10^{-4} \mathrm{Bg} / \mathrm{m}^{3}$ to $7.6 \times 10^{-2} \mathrm{Bg} / \mathrm{m}^{3}$, and the values of electrical conductivity were from $1.3 \mathrm{x}$ $10^{-14} \mathrm{~S} / \mathrm{m}$ to $3.1 \times 10^{-14} \mathrm{~s} / \mathrm{m}$.

The clear inverse correlation between radon concentration and electrical conductivity was sometimes found in mid ocean and also over the Philippine sea.
\end{abstract}

\section{Introduction}

To know the distribution trend of radon, its daughters and aerosols dispersing from the land to wide area over the ocean, and to know the variation trend of electrical conductivity in the atomosphere on the sea, we have repeatedly made the observations of them by ship since 1975 (Mochizuki, 1978, 1982 ; Mochizuki et al., 1981, 1984, 1985, 1992 ; Tanji et al., 1992, 1993).

We have made the measurements over the Indian Ocean via the South China Sea and the Philippine Sea from July to September, 1993, on board the research vessel "Hakuho Maru", Ocean Research Institute, University of Tokyo.

We will present here some observational results on the radon concentration and the atmospheric electrical conductivity found over the Indian Ocean, the South China sea and the Philippine Sea, and discuss first the distribution trend of radon and second the inverse correlation between radon concentration and electrical conductivity.

2. Instruments used in the observation cruise

a) Measurement of $\mathrm{Rn}-222$ concentration

We used semiconductor detector(HORIBA Ltd. Silicon Surface Barrier Type, 300SB 120L) for detecting alpha ray from radon daughters collected on an air filter. Alpha ray spectrometory was adopted for the measurement of Po- 218 and Po-214. Assuming the radioactive equilibrium state among $\mathrm{Rn}-222$, $\mathrm{Po}-218, \mathrm{~Pb}-214$ and $\mathrm{Bi}-214$, the radon concentration was estimated from the alpha disintegration rates of Po-218 and Po-214 (Mochizuki, 1982). 
The measurement was made at an interval of about 4 hours or 8 hours through the full period of the cruise. Collection time of radon daughters and analyzing time were both set at $8000 \mathrm{sec}$.

Radon daughters were collected on a membrane filter(TOYO-ROSHI Ltd. TM-100) with a suction pump at flow rate of $60 \mathrm{l} / \mathrm{min}$. Sample air was introduced through a sampling hole of laboratory at height about $10 \mathrm{~m}$ above the sea surface.

b) Measurement of atmospheric electrical conductivity

We used a Gerdien-type apparatus for the measurement of atmospheric electrical conductivity. The apparatus was set on the starboard side of the upper deck at height about $12 \mathrm{~m}$ above the sea surface. We measured alternately positive and negative conductivities at an interval of five minutes and continued it through the full period of the cruise.

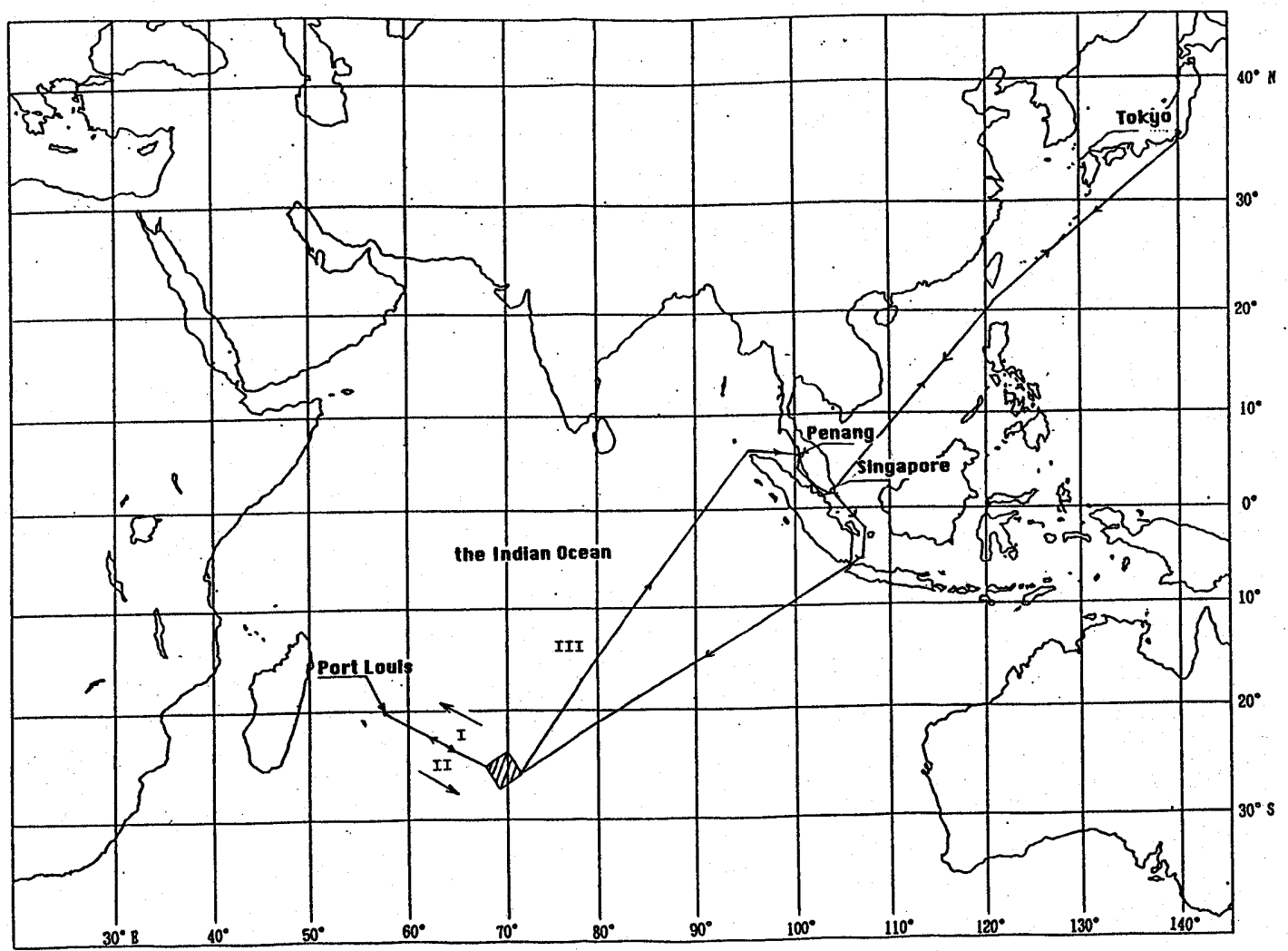

Fig.1. Cruise route of KH93-3 expedition, $8 \mathrm{Jul}$. to $17 \mathrm{sep} .1993$, by the research vessel Hakuho Maru, Ocean Research Institute, University of Tokyo.

\section{Discussion of observation results}

Cruise routes of the expedition are shown in Fig.1. Results obtained in each part on the routes are presented in Fig. 2 and Fig.3. 


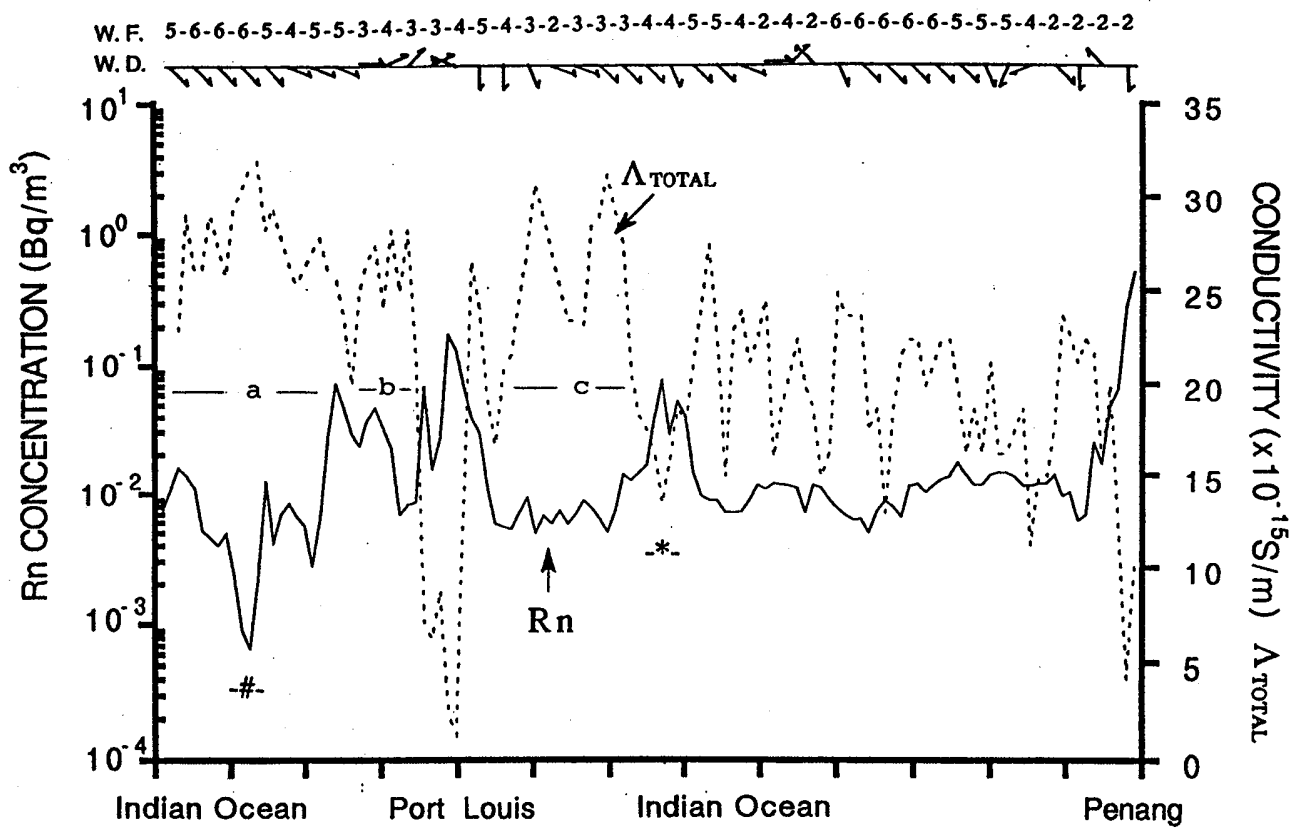

Fig.2. Radon concentration and electrical conductivity in the atmosphere over the Indian Ocean.

We referred to wind direction and wind force and other data obtained by the meteorological instruments on the ship.

wind direction and wind force (in Beaufort wind scale) are shown in the upper part of each figure.

In Fig.2 and Fig.3 the abscissa does not represent the ship position on the cruise route but the time scale devided in equal interval of 2.5 days.

The values plotted were obtained at the time when each measurement was made on the cruise route. The ship position is known from the time on the abscissa.

Figure 2 shows the observation results obtained on the cruise routes I,II and III shown in Fig. 1 . The continuous measurements of concentration of radon daughters and electrical conductivity were started on 1 Aug. (GMT) from around

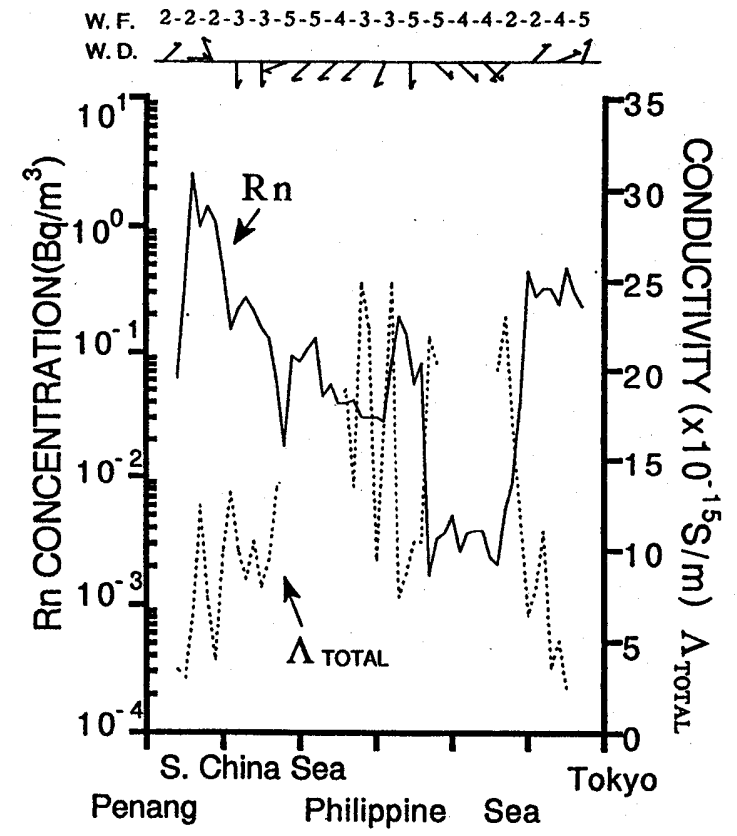

Fig.3. Radon concentration and electrical conductivity in the atmosphere over the South China Sea and the Philippine Sea. 
the spot $\left(25^{\circ} \mathrm{S}, 69^{\circ} \mathrm{E}\right)$ shown as a shaded square in Fig.1.

The vessel arrived at Port Louis on 10 Aug.(GMT) via the spot described above and marked by \# in Fig. 2 .

The measurments of them were continued also during the vessel was at anchor.

The vessel departed from Port Louis on 14 Aug. (GMT) and arrived at Penang on 2 Sep. (GMT) via again the spot described above and marked by * in Fig. 2 .

As is seen in Fig.2;

a) The radon concentration in the atmosphere over the mid Indian Ocean was found to be ranged from $6.6 \times 10^{-4} \mathrm{Bg} / \mathrm{m}^{3}$ to $7.6 \times 10^{-2} \mathrm{~Bq} / \mathrm{m}^{3}$, and the value of electrical conductivity was from $1.3 \times 10^{-14} \mathrm{~s} / \mathrm{m}$ to $3.1 \times 10^{-14} \mathrm{~s} / \mathrm{m}$. The lowest concentration of radon and the highest value of electrical conductivity were found on the ocean around the spot marked by \# on 4 Aug. (GMT). The mean level of radon concentration measured during the cruise was about $1 \times 10^{-2} \mathrm{Bg} / \mathrm{m}^{3}$. This concentration level is similar to that obtained over the south-eastern Pacific Ocean (Mochizuki et al., 1985; Tanji et al., 1992).

b) Regardless of at the same spot on the Ocean shown in Fig.1, variation patterns were different for different times as marked by \# and * in Fig.2. In the observation from $3 \mathrm{Aug}$. to $4 \mathrm{Aug}$. (mark \#), abrupt decrease of radon was seen, although its concentration level was extremely low, and electrical conductivity showed considerably high values. While, in the observation from 19 Aug. to 21 Aug. (mark *), considerable increase and decrease of radon, although, its concentration level was still fairly low, were seen and the electrical conductivity showed the abrupt change between low and high values corresponding to radon increase and decrease.

Referring to the weather map shown in Fig.4 and considering the wind directions shown in Fig.2, the increase of radon measured from 19 Aug. to 21 Aug. seemed to be under the considerable influence from Australian continent.

At the present, detailed analysis of air mass trajectory has not yet been made. However, roughly speaking, the extremely low level of radon concentration measured from $3 \mathrm{Aug}$. to $4 \mathrm{Aug}$. is thought to be due to the aged air mass that had passed long over the Antarctic Ocean.

Clear inverse correlation between radon concentration and electrical conductivity was seen in the areas ( $a, b$ and $c$ in Fig.2) over the ocean from vicinity of the spot (\# in Fig.2) to Port Louis and from Port Louis to the $\operatorname{spot}(*)$.

Figure 3 shows the observation results obtained on the cruise route from Penang to Tokyo.

As it is seen on the cruise route shown in Fig.1, many islands are scattered along the route and also Asian Continent lies on the left side of the vessel. Corresponding to this, the concentration of radon and electrical conductivity showed considerable variations when the vessel approached to and departed from the vicinity of islands. 
The concentration of radon measured here clearly showed a considerable influence from islands and Asian continent. The radon concentration was ranged from $1.7 \times 10^{-2} \mathrm{~Bq} / \mathrm{m}^{3}$ to $1.9 \times 10^{-1} \mathrm{~Bq} / \mathrm{m}^{3}$, and the mean concentration level of radon was higher than that obtained over the Indian Ocean.

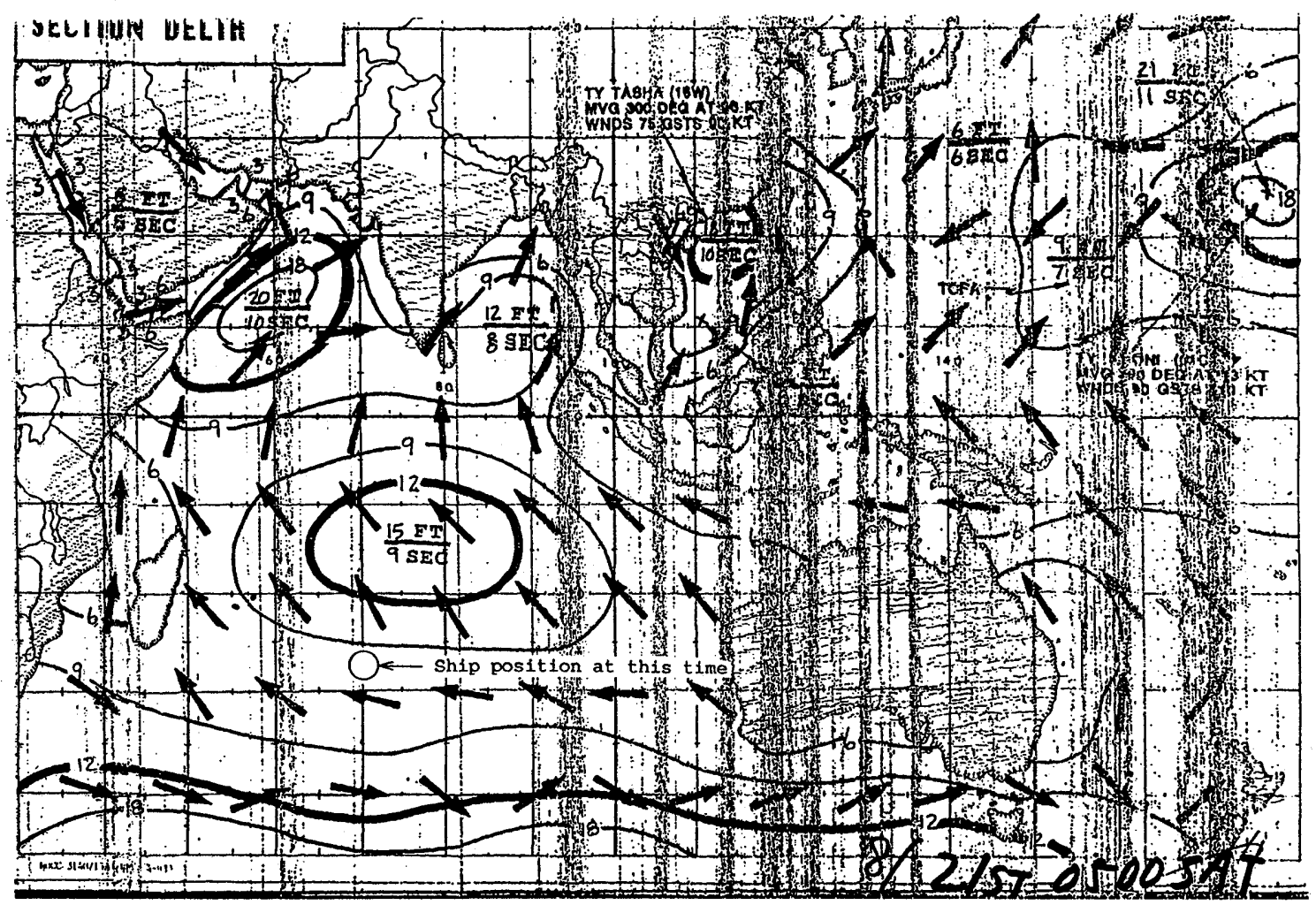

Fig. 4 Weather map of the Indian Ocean on 21 Aug. 1993.

In the observation period from $11 \mathrm{sep}$. to $13 \mathrm{sep}$. when the vessel was on the Pilippine Sea, for escape from the typhoon just taking place over the sea of south of Formosa, the vessel cruised along the east side of typhoon at a considerable distance departed from the scheduled route.

The radon concentration measured on this occasion is thought to be from the air mass that had passed over the Pacific Ocean, and it showed a considerably low level from $1.7 \times 10^{-3} \mathrm{Bg} / \mathrm{m}^{3}$ to $5.0 \times 10^{-3} \mathrm{Bg} / \mathrm{m}^{3}$.

\section{Concluding remarks}

Observational evidences obtained from the cruise toward the Indian Ocean, in the period from July to september 1993, are summarized as follows;

a) On the mid Indian Ocean, radon concentrarion levels were found to be ranged from $6.6 \times 10^{-4} \mathrm{~Bq} / \mathrm{m}^{3}$ to $7.6 \times 10^{-2} \mathrm{~Bq} / \mathrm{m}^{3}$, and the values of electrical conductivity were from $1.3 \times 10^{-14} \mathrm{~s} / \mathrm{m}$ to $3.1 \times 10^{-14} \mathrm{~s} / \mathrm{m}$.

b) The lowest value of radon concentration, $6.6 \times 10^{-4} \mathrm{~Bq} / \mathrm{m}^{3}$, was found around the spot $25^{\circ} \mathrm{S}, 69^{\circ} \mathrm{E}$.

c) On the South China Sea, the radon concentration level was ranged from 1.7 
$\times 10^{-2} \mathrm{~Bq} / \mathrm{m}^{3}$ to $1.9 \times 10^{-1} \mathrm{~Bq} / \mathrm{m}^{3}$.

d) Clear inverse correlation between radon concentration and electrical conductivity was found in the observation over the mid Indian Ocean.

Acknowledgment. The authors wish to express their sincere thanks to Dr. K. Tamaki and the staff of the Ocean Research Institute, University of Tokyo, for kindly giving us the opportunity of making our measurements on the research vessel Hakuho Maru. They also thank captain, officers and crew aboard the Hakuho Maru cruise, KH-93-3, for their cooperation in the observations.

\section{References}

Mochizuki, S., Comparison of natural atmospheric radioactivity appeared over Hachijo Island and Miyake Island in early spring, J. Meteor. Soc. Japan, $56,52-56,1978$.

Mochizuki,S. and T. Tanji, Radioactive aerosols in the atmosphere over the ocean of south Japan Islands III, Res. Lett. Atmosph. Electr., 1, 9-14, 1981 (in Japanese).

Mochizuki,S., Radon and its daughters in the maritime atmosphere near Japan Island, J. Meteor. Soc. Japan, 60, 787-796, 1982.

Mochizuki,S., T. Tanji, M. Okino, K. Orikasa, and N. Matsumura, Natural atmospheric radioactive aerosols in the atmosphere over the Pacific Ocean of the northern hemisphere, Aerosols (Proc. 1st Int. Aerosol Conf. ed. by Liu, Pui, Fissan) 307-310, 1984.

Mochizuki, S., T. Tanji, M. Okino, and Y. Sato, Rn-222 and atmospheric conductivity in the atmosphere over the Pacific Ocean of the nothern hemisphere, Res. Lett. Atomosph. Electr. 5, 81-87, 1985.

Tanji,T., M. Okino, I. Sugioka, and S. Mochizuki, Radon and its daughters in the atmosphere over the Equatorial Pacific Ocean, J. Radon Protec. Dosim., 45, 399-401, 1992 .

Tanji, T., M. Okino, S. Mochizuki, and I. Sugioka, Atmospheric electrical conductivity and radon daughters in the atmosphere over the Pacific Ocean, J. Atmosph. Electr. 13, 59-63, 1993.

(Received June 3, 1995; revised July 19, 1995; accepted July 25, 1995.) 